\title{
TRPM8 in prostate cancer cells: a potential diagnostic and prognostic marker with a secretory function?
}

\author{
Lei Zhang ${ }^{1}$ and Gregory J Barritt ${ }^{2}$
}

\author{
${ }^{1}$ Office of Chemical Safety (MDP 88), Therapeutic Goods Administration, Department of Health and Ageing, \\ PO Box 100, Woden ACT 2606, Australia \\ ${ }^{2}$ Department of Medical Biochemistry, School of Medicine, Faculty of Health Sciences, Flinders University, \\ GPO Box 2100, Adelaide, South Australia 5001, Australia
}

(Requests for offprints should be addressed to G Barritt; Email: greg.barritt@flinders.edu.au)

\begin{abstract}
During the past 5 years it has emerged that the transient receptor potential (TRP) family of $\mathrm{Ca}^{2+}$ and $\mathrm{Na}^{+}$-permeable channels plays a diverse and important role in cell biology and in pathology. One member of this family, TRPM8, is highly expressed in prostate cancer cells but the physiological and pathological functions of TRPM8 in these cells are not known. Here we address these questions, and the issue of whether or not TRPM8 is an effective diagnostic and prognostic marker in prostate cancer. TRPM8 is known to be activated by cool stimuli $\left(17-25^{\circ} \mathrm{C}\right)$ and cooling compounds such as menthol. The activation mechanism(s) involves voltage sensing of membrane potential, phosphatidylinositol 4,5-bisphosphate and $\mathrm{Ca}^{2+}$. In addition to prostate cancer cells, TRPM8 is expressed in sensory neurons where it acts as a sensor of cold. In prostate epithelial cells, expression of TRPM8 is regulated by androgen and is elevated in androgen-sensitive cancerous cells compared with normal cells. While there is some evidence that in prostate cancer cells $\mathrm{Ca}^{2+}$ and $\mathrm{Na}^{+}$inflow through TRPM8 is necessary for survival and function, including secretion at the apical membrane, the function of TRPM8 in these cells is not really known. It may well differ from the role of TRPM8 as a cool sensor in sensory nerve cells. Androgen unresponsive prostate cancer is difficult to treat effectively and there are limited diagnostic and prognostic markers available. TRPM8 is a potential tissue marker in differential diagnosis and a potential prognostic marker for androgen-unresponsive and metastatic prostate cancer. As a consequence of its ability to convey $\mathrm{Ca}^{2+}$ and $\mathrm{Na}^{+}$and its expression in only a limited number of cell types, TRPM8 is considered to be a promising target for pharmaceutical, immunological and genetic interventions for the treatment of prostate cancer.
\end{abstract}

Endocrine-Related Cancer (2006) 13 27-38

\section{Introduction}

TRPM8 is a member of the transient receptor potential (TRP) family of $\mathrm{Ca}^{2+}$-permeable non-selective cation channels, and belongs to the TRPM (melastatin) subfamily of TRP proteins. There are seven main subfamilies of TRP proteins. In addition to the TRPM subfamily, these are: TRPC (canonical or classical), TRPV (vanilloid), TRPP (polycystin), TRPML (mucolipin), TRPA (ankyrin-like) and TRPN (no mechanoreceptor potential C, NOMPC) (reviewed in Clapham 2003, Montell 2005, Nilius et al. 2005). TRPM8 was discovered as a protein that is upregulated in prostate and in some other types of cancer cells (Tsavaler et al. 2001). However, TRPM8 is also expressed in sensory neurons (McKemy et al. 2002, Peier et al. 2002, Zhang et al. 2004) and is one of two cold-sensing TRP channels, the other being TRPA1 (Story et al. 2003, McKemy 2005). By contrast, heat and heating compounds are sensed by several members of the TRPV subfamily, TRPV1, V2, V3, and V4 (reviewed in Clapham 2003).

Although there is evidence that TRPM8 is involved in thermo and pain sensation in sensory neurons, the knowledge of the functions of TRPM8 in other cell types, including prostate cancer cells, is very limited. 


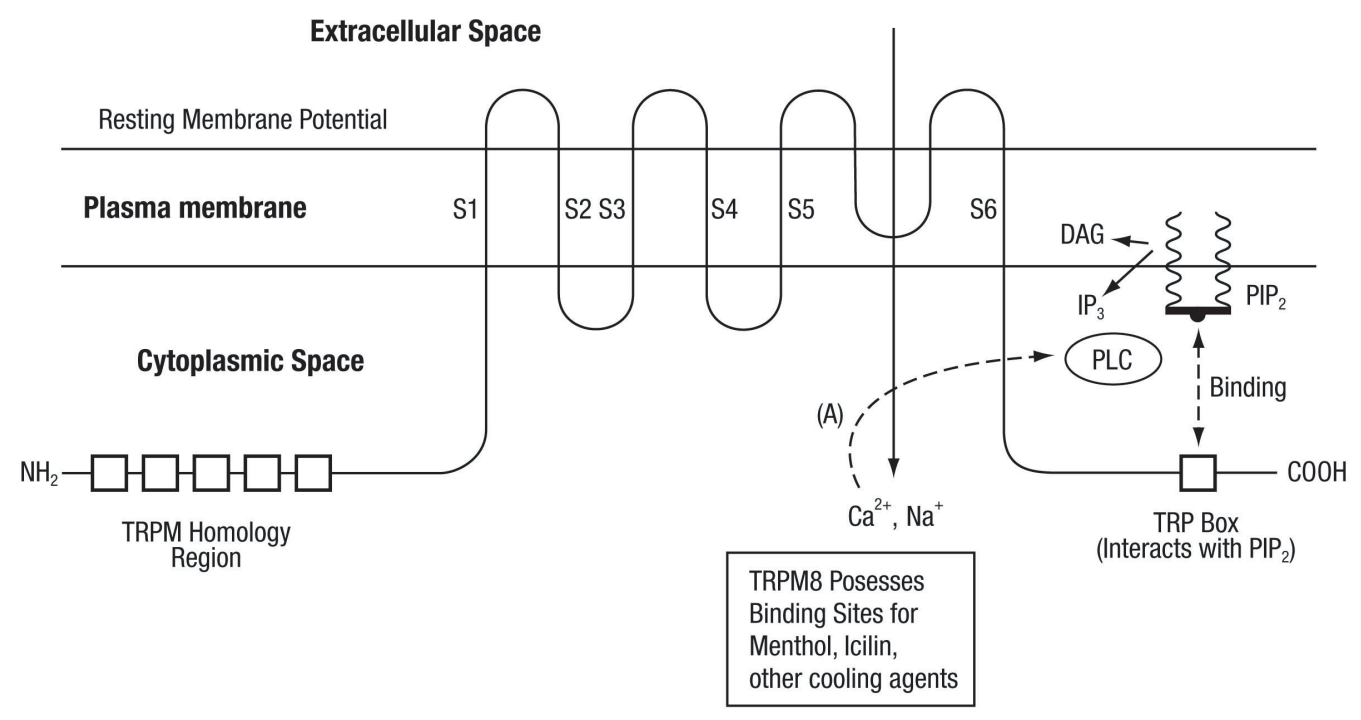

Figure 1 A schematic representation of the structure of the TRPM8 polypeptide showing the main features of the membranespanning domains (S1-S6), cytoplasmic amino terminus, and cytoplasmic carboxy terminus. TRPM8 is activated by cold or menthol (or other cooling agents) in a process that involves a change in the activation curve (response) to membrane potential. Phosphatidylinositol 4,5-bisphosphate $\left(\mathrm{PIP}_{2}\right)$ and, in some cases, the presence of $\mathrm{Ca}^{2+}$ at the cytoplasmic mouth of the channel form part of the activation mechanism. $\mathrm{PIP}_{2}$ is thought to interact with the TRP domain in the carboxy terminus. The activated channel is desensitised by the action of $\mathrm{Ca}^{2+}$ at the cytoplasmic mouth of the channel which activates $(\mathrm{A})$ a $\mathrm{Ca}{ }^{2+}$-sensitive phospholipase C (PLC) (possibly PLC $\gamma 1$ ) leading to the hydrolysis of $\mathrm{PIP}_{2}$ to generate inasitol 1,4,5-triphosphate (IP 3 ) and diacylglycerol (DAG) and inactivation of the channel. The scheme is based on references cited in the text.

The detection of TRPM8 in a number of normal urogenital tissues and the profile of up-regulated expression of TRPM8 in prostate cancer and other cancer cells suggest that this $\mathrm{Ca}^{2+}$-permeable channel may play diverse roles in different tissues.

\section{Structure of TRPM8}

The human TRPM8 polypeptide consists of 1104 amino acids (Tsavaler et al. 2001, Peier et al. 2002). The predicted secondary structure includes six membrane-spanning domains and cytoplasmic amino and carboxy terminal domains (Fig. 1). The S1-S4 transmembrane domains exhibit weak voltage-sensing properties. It is proposed that the pore of the channel is composed of the region between the S5 and S6 membrane-spanning sequences in a tetramer comprising, most likely, four TRPM8 polypeptides (McKemy et al. 2002). The amino terminus contains several TRPM homology sequences, while the large carboxy terminus contains the TRP box (a sequence common to each member of the TRPV, TRPC and TRPM families) and eight potential N-linked glycosylation sites. Unlike many other members of the TRP family, no ankyrin repeat elements are present in the amino terminus (Tsavaler et al. 2001, Peier et al. 2002, Clapham 2003). Electrophysiological studies conducted with TRPM8 heterologously expressed in mammalian cells indicate that the protein mediates an outwardly rectifying current with a selectivity for $\mathrm{Ca}^{2+}: \mathrm{Na}^{+}$of 3:1 (McKemy et al. 2002, Peier et al. 2002).

\section{Activation signals and mechanisms for TRPM8}

TRPM8 can be experimentally activated by cooling (temperatures between 10 and $25^{\circ} \mathrm{C}$ ), membrane depolarisation and by chemical agents. The voltagedependent activation of TRPM8 is not strong and the voltage sensor is not known although it has been suggested that it is located in the carboxy terminus of TRPM8 (Nilius et al. 2005). Chemical activators of TRPM8 include menthol and icilin, and other cooling compounds, such as menthone, eucalyptol, geraniol and linalool (Fig. 2a) (McKemy et al. 2002, Peier et al. 2002, Behrendt et al. 2004, Brauchi et al. 2004, Voets et al. 2004). Capsazepine (shown in Fig. 2b) is an antagonist of menthol activation of TRPM8 (Behrendt et al. 2004). Other antagonists include 
(a) TRPM8 Chemical Activators<smiles>CC(C)[C@H]1CC[C@@H](C)C[C@H]1O</smiles><smiles>O=C1NC(c2cccc([N+](=O)[O-])c2)=CCC1c1ccccc1O</smiles>

Menthol<smiles>CC(C)=CCCC(C)=CCO</smiles>

Geraniol

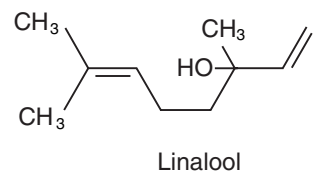

(b) TRPM8 Chemical Antagonists

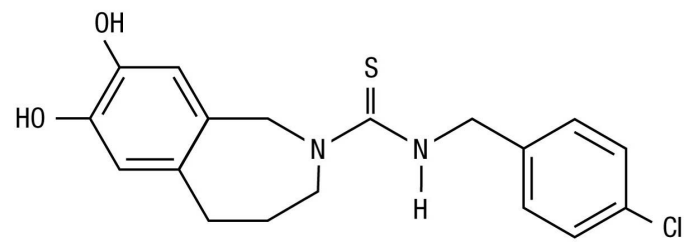

Capsazepine

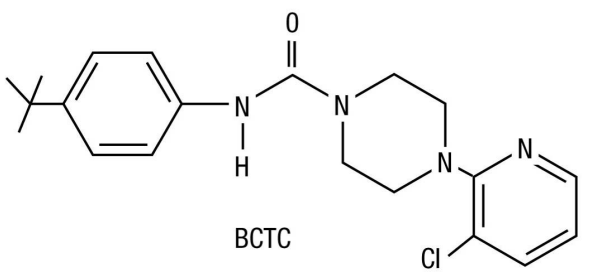

Figure 2 The structures of some chemical activators (a) and inhibitors (b) of the TRPM8 channel.

$N$-(4-tert.butylphenyl)-4-(3-chloropyridin-2-yl)tetrahydropyrazine-1 $(2 \mathrm{H})$ carboxamite (BCTC) (Fig. 2b) and thiol BCTC (Behrendt et al. 2004). The activation of TRPM 8 by cold and icilin, but not by menthol, is modulated by intracellular $\mathrm{pH}$ (Andersson et al. 2004).

The results of recent studies investigating the mechanism of activation of TRPM8 by cooling have provided evidence that cold or menthol change the weak voltage-dependent activation curves (i.e. change the activation energy) (Voets et al. 2004). It seems that menthol functions as a modifier of TRPM8 channel gating, shifting the activation curve to physiological membrane potentials. Thus membrane potential plays a critical role in the activation mechanism for TRPM8 (Brauchi et al. 2004, Voets et al. 2004, Hui et al. 2005).

Another agent that plays an important role in the activation of TRPM8 is phosphatidylinositol 4,5bisphosphate $\left(\mathrm{PIP}_{2}\right)$. Liu \& Qin (2005) showed that the inactivation (desensitisation) of the TRPM8 channel is prevented by inhibitors of phospholipid phosphatases. Moreover, the application of exogenous $\mathrm{PIP}_{2}$ was found to both activate the channel directly and to restore activity after desensitisation (Liu \& Qin 2005). Using a slightly different experimental strategy, Rohacs et al. (2005) provided evidence that $\mathrm{PIP}_{2}$ is necessary for the activation of TRPM8 by cold or cooling agents. Moreover, $\mathrm{PIP}_{2}$ itself (in the absence of cold or a cooling agent) could also activate the channel. Cold or a cooling agent increases the apparent affinity of TRPM8 for $\mathrm{PIP}_{2}$ and it is proposed that cooling activates the channel by increasing the sensitivity to $\mathrm{PIP}_{2}$. Evidence has been obtained to indicate that $\mathrm{PIP}_{2}$ binds to positive changes in the TRP motif in the cytoplasmic carboxy terminus (shown schematically in Fig. 1). As pointed out by Rohacs et al. (2005), the activation mechanisms of TRPM8 are undoubtedly complex. It is likely that the role of $\mathrm{PIP}_{2}$ is part of, or linked to, the effects of cold and cooling agents in changing the activation energy of the channel (Voets et al. 2004). Confirmation of these ideas will require further experiments.

$\mathrm{Ca}^{2+}$ plays an important role in regulating the activity of TRPM8. Recent studies by Chuang et al. (2004) have shown that the activation of TRPM8 by icilin requires an increase in the cytoplasmic $\mathrm{Ca}^{2+}$ concentration $\left(\left[\mathrm{Ca}^{2+}\right]_{\text {cyt }}\right)$ at the cytoplasmic mouth of the channel i.e. the flow of $\mathrm{Ca}^{2+}$ through the channel (Fig. 1). They suggested that this requirement for $\mathrm{Ca}^{2+}$ might represent the coincidence detection of signals by TRPM8 (Chuang et al. 2004). These authors also provided evidence that indicates that the region of the TRPM8 polypeptide that appears to interact with icilin is similar in structure to the region of hot-sensing TRPV1 that interacts with capsaicin.

$\mathrm{Ca}^{2+}$ inflow also plays a role in modulating (desensitising) TRPM8. Thus it has been found that $\mathrm{Ca}^{2+}$ inflow through TRPM8 activates phospholipase C (PLC) (possibly PLC $\gamma 1$ ) which hydrolyses PIP $_{2}$, leading to a decrease in $\mathrm{PIP}_{2}$ and inhibition (desensitisation) of channel activity (Fig. 1) (Rohacs et al. 2005). This may be one of numerous examples (for many types of $\mathrm{Ca}^{2+}$ permeable channel) of the physiological importance of limiting the amount of $\mathrm{Ca}^{2+}$ which enters the cell via the open channel, and hence the necessity of there being effective mechanisms for achieving this.

Several research groups have compared the properties of the cold-sensing TRPM8 channels with those of the hot-sensing TRPV channels. It was found that TRPM8 is inhibited by 2-aminoethoxydiphenyl borate (2-APB) (Hu et al. 2004). 2-APB inhibits several types 
Table 1 Distribution of TRPM8 in normal and cancerous tissues and cells

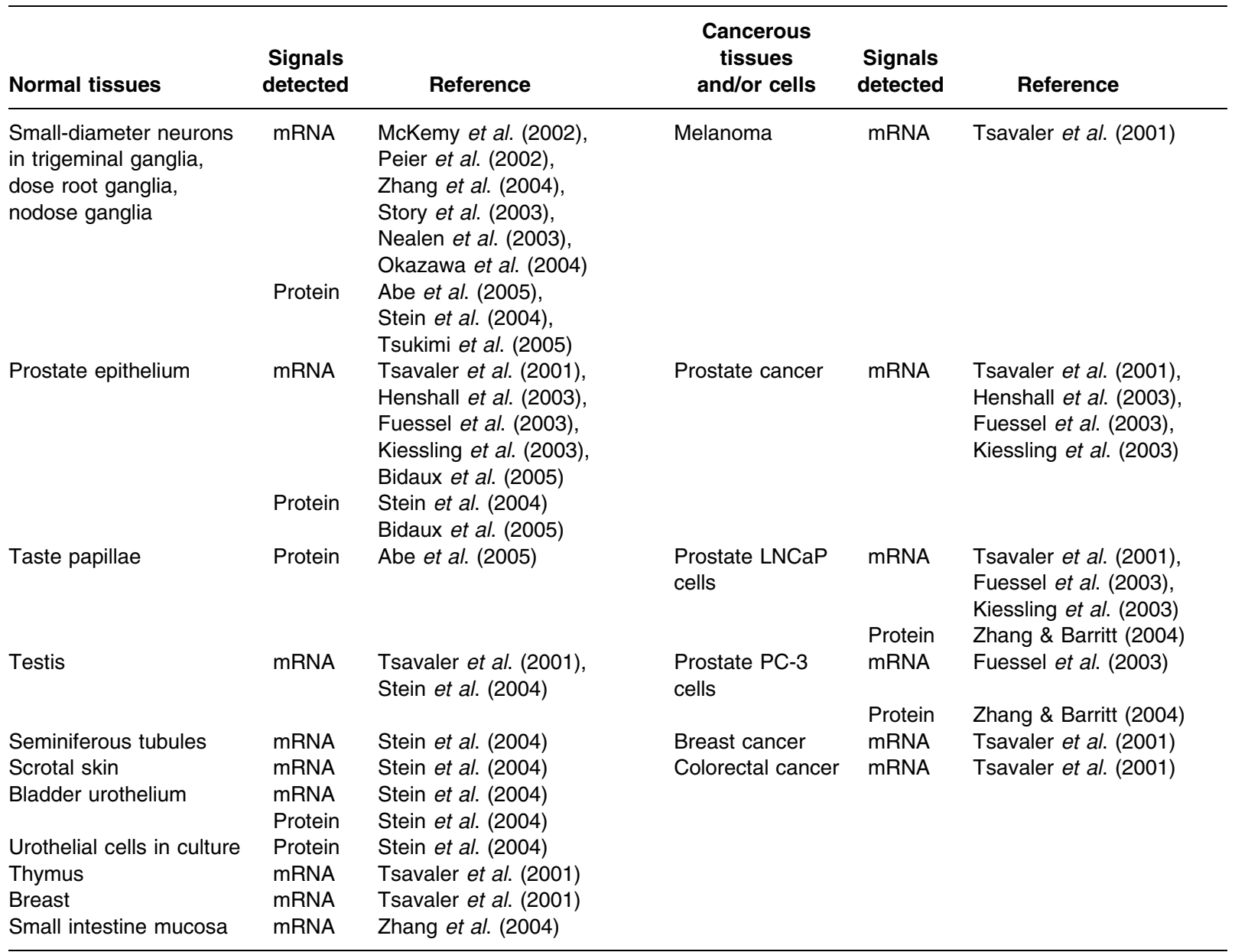

of plasma membrane $\mathrm{Ca}^{2+}$-permeable channels and, under some conditions, it also inhibits inositol 1,4,5trisphosphate receptors (Bootman et al. 2002). 2-APB can be used to distinguish TRPM8 from TRPV1, V2 and V3, since it activates TRPV1, V2 and V3 but inhibits TRPM8 (Hu et al. 2004). These observations most likely reflect differences in either the pores of the channels or in the activation mechanisms.

Other similarities and differences between TRPM8 and TRPV1 have been described by Weil et al. (2005) using the whole cell patch-clamp technique to study channel function. They showed that TRPM8 activity is modified by ethanol, TRPM8 is not affected by extracellular $\mathrm{H}^{+}$whereas TRPV1 does respond to extracellular $\mathrm{H}^{+}$, and many of the TRPV1 antagonists, including capsazepine, BCTC, (2R)-4-(3-chloro-2 pyridinyl)-2-methyl- $N$-[4-(trifluoromethyl)phenyl]-1 piperazonecarboxamide (CTPC) and SB-452533, are also antagonists of TRPM8. These results have implications for both the structure and mechanism of activation of TRPM8, and also highlight potential difficulties in developing pharmaceutical interventions selective for TRPM8.

\section{Expression and functions of TRPM8 in neuronal cells}

The most clearly defined physiological function of TRPM8 is in sensory neuronal cells. It is proposed that TRPM8 channels constitute the cold sensors that detect ambient temperature. TRPM8 is found in painand temperature-sensing neurons (including smalldiameter dorsal root ganglion neurons, trigeminal ganglia neurons and nodose ganglion neurons (McKemy et al. 2002, Peier et al. 2002, Thut et al. 2003, Babes et al. 2004, Tominaga \& Caterina 2004, Zhang et al. 2004) and taste papillae (Abe et al. 2005)), and also in many other tissues including testis, scrotal 
skin, bladder urothelium (Stein et al. 2004), thymus, breast, ileum and in melanoma, colorectal cancer and breast cancer cells (Tsavaler et al. 2001, Zhang et al. 2004). The known tissue distribution of the TRPM 8 protein is summarised in Table 1. Further evidence for the function of TRPM8 as a sensor for cold in sensory neuronal cells has come from the transient transfection of cultured hippocampal neurones with TRPM8. This conferred sensitivity to cold and menthol that is not exhibited by non-transfected hippocampal neurones (de la Pena et al. 2005).

TRPM8 facilitates $\mathrm{Ca}^{2+}$ and $\mathrm{Na}^{+}$inflow across the plasma membrane and may mediate the release of $\mathrm{Ca}^{2+}$ from the endoplasmic reticulum (ER) since some TRPM8 is found expressed in the ER as well as in the plasma membrane (Chuang et al. 2004). The activation of TRPM8 and subsequent inflow of $\mathrm{Na}^{+}$and $\mathrm{Ca}^{2+}$ leads to depolarisation of the plasma membrane. A cold stimulus is most likely the physiological activator of TRPM8 in sensory neurons. However, it has also been suggested that an (unidentified) endogenous menthol-like ligand may act as a physiological activator of TRPM8 (McKemy et al. 2002).

\section{Expression of TRPM8 in prostate cancer cells}

Tsavaler et al. (2001) found high levels of TRPM8 in both benign prostate hyperplasia and in prostate carcinoma cells, and low levels in normal (noncarcinoma) prostate epithelial cells (Fig. 3). Henshall et al. (2003) observed that with anti-androgen therapy, the expression of TRPM8 was greatly reduced. They also showed that TRPM8 expression is decreased when prostate cancer cells become androgen-independent, suggesting that TRPM8 is regulated by androgens (Henshall et al. 2003). The degree of expression of TRPM8 in prostate cancer tissue appears to be quite variable (Tsavaler et al. 2001, Henshall et al. 2003, Kiessling et al. 2003). Kiessling et al. (2003) examined prostate cancer tissue from 33 prostate cancer patients and found high but variable levels of TRPM8 mRNA expression in both tumorigenic and normal prostate tissue. However, a statistically significant greater expression of TRPM8 was observed in tumorigenic compared with normal tissue. No clear correlation of TRPM8 expression with the severity of prostate cancer was, however, observed.

Fuessel et al. (2003) have studied the expression of TRPM8 in relation to other established and potential prostate cancer markers. They found that in both malignant and non-malignant tissue samples, prostate specific antigen (PSA) is expressed at the highest level (in terms of absolute amounts of mRNA), with lower levels of human kallikrein 2 (hK2) and TRPM8, and very low levels of prostate stem cell antigen (PSCA). However, on the basis of relative amounts of mRNA, TRPM8 expression (but not PSA expression) in malignant tissue was significantly greater than that in non-malignant tissue. When only organ-confined prostate cancer tissue samples were considered, this difference for TRPM8 was greater, and a difference between malignant and non-malignant tissue was also observed for PSA.

In malignant tissue specimens from patients with a total serum PSA concentration in the 'grey-zone' of 4-10 ng/ml, TRPM8 mRNA, but not PSA mRNA was significantly elevated. Thus the detection of TRPM8 expression could be useful in the differential diagnosis of prostate cancer in biopsy specimens to facilitate therapeutic decisions particularly in ambiguous cases often found in this total PSA 'grey-zone'. More interestingly, in identified groups of low- and highgrade prostate cancer, significant differences in expression between malignant and non-malignant tissue samples were found for TRPM8 but not for other prostate cancer markers, including PSA. It was concluded that, compared with the other markers (PSA, hK2 and PSCA), TRPM8 is a more specific indicator of prostate cancer and a potential candidate for targetted gene therapy or other interventions (Fuessel et al. 2003). However, as discussed below, expression of TRPM8 in prostate cancer cells is closely linked to the presence of a functional androgen receptor. Bidaux et al. (2005) have drawn attention to the complexities caused by this link and hence in using TRPM8 as a prognostic marker for prostate cancer.

A significant proportion of TRPM8 is observed in the plasma membrane of prostate cancer cells, although the protein has also been observed in intracellular membranes (Zhang \& Barritt 2004). Extracellular domains of the protein can potentially activate cytotoxic T-lymphocytes. One such region, the GLMKYIGEV, has been identified (Kiessling et al. 2003). This may provide an endogenous mechanism that enhances the destruction of prostate cancer cells expressing TRPM8 - part of the normal immunological defence mechanisms. Loss of TRPM8 expression in metastatic prostate cancer cells may, therefore, be associated with a reduction in prostate cancer cell destruction. On the other hand, the activation of cytotoxic T-lymphocytes by the GLMKYIGEV region may offer the possibility of an immunotherapeutic approach to killing prostate cancer cells based on this 

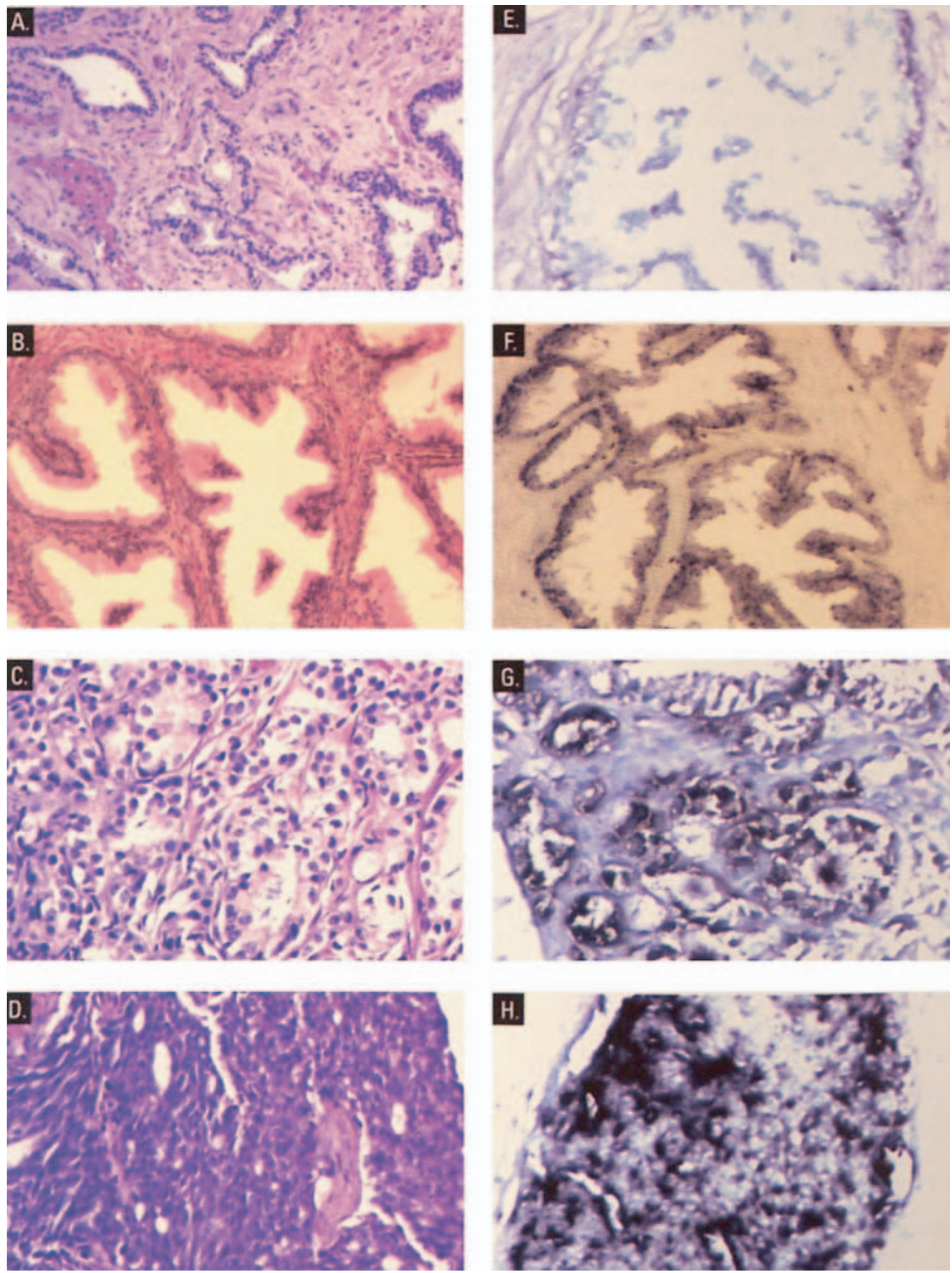
or another TRPM8 peptide as target (Kiessling et al. 2003).

\section{Regulation of TRPM8 by androgens in prostate cancer cells}

The early studies of Tsavaler et al. (2001) and Henshall et al. (2003) suggested that expression of TRPM8 in prostate cancer cells is regulated by androgen. This has been confirmed in recent more direct experiments. Zhang \& Barritt (2004) reported androgen-dependent TRPM8 expression in the androgen-responsive LNCaP cell line, but not in the androgen-unresponsive PC-3 cell line. Bidaux et al. (2005) have shown that expression of TRPM8 in prostate epithelial cells requires a functional androgen receptor. They used an anti-androgen antagonist and also transfected cDNA encoding the androgen receptor into PNT1A cells (which have lost androgen receptor). The response of TRPM8 to androgens was demonstrated in prostate cancer cell lines, and in primary cultures of normal, hyperplasic and cancerous prostate epithelial cells (Bidaux et al. 2005). The extremely low level of androgen receptor expression in androgen refractory prostate cancer cells such as the PC-3 cell line (Culig et al. 1993) probably contributes to the much lower level of TRPM8 gene expression and the lack of response to androgen regulation (Zhang \& Barritt 2004).

The question of what mechanism underlies the androgen regulation of TRPM8 in androgenresponsive prostate cancer cells has been addressed, and several putative androgen response elements have been detected (Zhang \& Barritt 2004, Bidaux et al. 2005). Analysis of $5^{\prime}$ flank regions of the TRPM 8 gene using GenoMatix reveals that a region which spans $1500 \mathrm{bp}$ upstream of the transcription initiation code in the TRPM 8 gene may be the core promoter for TRPM8 DNA transcription. This promoter region contains a variety of putative transcriptional factor binding sites including at least three TATA boxes, a transcription factor Sp1, a transcript enhancer factor Tef, three NKX3.1 binding sites and an androgenresponsive element (Table 2, Fig. 4). The last mentioned exhibits a high degree of homology to a motif corresponding to the TRANSFAC androgenresponsive element consensus sequence (c.f. Zhang \& Barritt 2004, Bidaux et al. 2005). Further analysis reveals another nine putative androgen-responsive elements in the introns of the TRPM8 gene (Fig. 4), and two in the $3^{\prime}$ untranslated region. It is possible that in androgen-responsive prostate cancer cells (which have functional androgen receptors) the androgenandrogen receptor complex binds with androgen response elements in either the promoter region or introns in the TRPM8 gene. Together with other transcription co-factors, this may initiate TRPM8 gene transcription.

NKX3.1 is an androgen-regulated homeodomain protein that is predominantly localised in the adult prostate in men (He et al. 1997, Prescott et al. 1998) and is a candidate tumour-suppressor oncogene (Lundgren et al. 1988, Carter et al. 1990, Phillips et al. 1994, Voeller et al. 1997). Thus the three putative prostate-specific NKX3.1 binding sites in the TRPM8 promoter region are compatible with the androgendependence and prostate-predominant expression profile of TRPM8.

\section{Physiological functions of TRPM8 in prostate cancer cells}

Evidence from immunofluorescence experiments indicates that, in the androgen-responsive $\mathrm{LNCaP}$ cell line, the TRPM8 protein is expressed in the plasma membrane and ER, and acts as a $\mathrm{Ca}^{2+}$-permeable channel (assessed using fura- 2 to measure increases in the $\left[\mathrm{Ca}^{2+}\right]_{\mathrm{cyt}}$ ) in each of these membranes (Zhang \& Barritt 2004). The results of experiments employing LNCaP cells, the TRPM8 antagonist capsazepine, and siRNA targetted to TRPM8 suggest that TRPM8 is required for cell survival. These results indicate that $\mathrm{Ca}^{2+}$ and $\mathrm{Na}^{+}$inflow through TRPM8 plays an essential role in cellular $\mathrm{Na}^{+}$and $\mathrm{Ca}^{2+}$ homeostasis in prostate epithelial cells.

It has been proposed that, in LNCaP cells, an increased growth rate correlates with an increase in the amount of $\mathrm{Ca}^{2+}$ in intracellular stores, whereas a decreased rate of growth correlates with a reduced load

Figure 3 In situ hybridisation of a TRPM8 RNA probe to normal prostate, benign prostate hyperplasia, and prostate cancer tissue. Serial sections $(4 \mu \mathrm{m})$ were stained with haematoxylin and eosin $(A, B, C$ and $D)$ or used in the in situ hybridisation with the TRPM8 RNA probe (E, F, G and H). (A and E) Normal prostate; (B and F) benign prostate hyperplasia; (C and $G)$ prostate cancer tissue (Gleason score 7); $(\mathrm{D}$ and $\mathrm{H}$ ) prostate cancer tissue (Gleason score 10). Magnifications: $A, \times 40 ; B$ and F, $\times 100 ; C, D, E, G$ and $H, \times 200$. From Tsavaler et al. (2001) reprinted with permission of the American Association for Cancer Research from Cancer Research. 
Table 2 Putative transcriptional binding sites identified in TRPM8 promoter region. (References are cited in the text.)

\begin{tabular}{|c|c|c|c|}
\hline Motif & Position (bp) & Strand & Sequence \\
\hline Myf (myogenic regulatory factors) & $\begin{array}{l}-59 \text { to }-48 \\
-295 \text { to }-284\end{array}$ & $\begin{array}{l}+ \\
+\end{array}$ & $\begin{array}{l}\text { agagaccagcag } \\
\text { agctaagagcag }\end{array}$ \\
\hline Tef (transcription enhancer factor) & $\begin{array}{l}-73 \text { to }-69 \\
-218 \text { to }-207\end{array}$ & $\begin{array}{l}+ \\
+\end{array}$ & $\begin{array}{l}\text { agctttcctcct } \\
\text { cgtattccactg }\end{array}$ \\
\hline $\begin{array}{l}\text { TATA box (Bound by TBP (TATA binding protein), a } \\
\text { component of TFIID) }\end{array}$ & $\begin{array}{c}-87 \text { to }-73 \\
-613 \text { to }-593 \\
-1266 \text { to }-1253\end{array}$ & $\begin{array}{l}+ \\
+ \\
+\end{array}$ & $\begin{array}{l}\text { ttataaaagctttcc } \\
\text { gtttaaaggggacag } \\
\text { ctatatatgtgcttg }\end{array}$ \\
\hline $\begin{array}{l}\text { Sp1 (GC box element/bound by transcription factors in the } \\
\text { Sp/KLF (kruppel-like factor) family) }\end{array}$ & -113 to -101 & + & agaaggcggggct \\
\hline $\begin{array}{l}\text { MyT1 (MyT1 zinc finger transcription factor involved in } \\
\text { primary neurogenesis) }\end{array}$ & -153 to -141 & + & cttaagtttttg \\
\hline NKX3.1 (prostate-specific homeodomain protein NKX3.1.) & $\begin{array}{l}-154 \text { to }-142 \\
-337 \text { to }-325 \\
-689 \text { to }-677\end{array}$ & $\begin{array}{l}+ \\
+ \\
+\end{array}$ & $\begin{array}{l}\text { gcttaagttttt } \\
\text { aattaagtattag } \\
\text { atttaagtaaaat }\end{array}$ \\
\hline Ets (c-Ets-2 binding site) & -603 to -593 & + & gacaggaaata \\
\hline ARE (androgen responsive element) & -242 to -257 & + & aaaataccatgttca \\
\hline $\begin{array}{l}\text { PSE.02 (proximal sequence element (PSE) of RNA } \\
\text { polymerase III-transcribed genes) }\end{array}$ & -446 to -428 & + & ctaatcttaattaagagct \\
\hline CEBP.02 (CCAAT/enhancer binding protein) & -519 to -505 & + & ggtatgaggaaagtt \\
\hline CEBPB. 01 (CCAAT/enhancer binding protein beta) & -837 to -817 & + & tgtcttgtgcaatca \\
\hline Myc (binding motif for Myc-Max dimers) & $\begin{array}{l}-697 \text { to }-688 \\
-1500 \text { to }-1491\end{array}$ & $\begin{array}{l}+ \\
+\end{array}$ & $\begin{array}{l}\text { ggcacgtgat } \\
\text { ggcacgtgcc } \\
\text { tgacctgtctgagccttggaa }\end{array}$ \\
\hline $\begin{array}{l}\text { MOK2 (ribonucleoprotein associated zinc finger protein } \\
\text { MOK-2 (human)) }\end{array}$ & -1051 to -1031 & + & \\
\hline P53 (tumor suppressor p53 ( $3^{\prime}$ half site)) & -1052 to -1032 & - & tccaaggctcagacaggtcat \\
\hline $\begin{array}{l}\text { ZBP-89 (zinc-finger binding protein- } 89 \text {. Transcriptional } \\
\text { repressor, binds to elements found predominantly in genes } \\
\text { that participate in lipid metabolism) }\end{array}$ & -1108 to -1086 & + & acageccccacccttccctactt \\
\hline Mef-2 (myocyte enhancer factor 2) & $\begin{array}{l}-1215 \text { to }-1204 \\
-1472 \text { to }-1461 \\
-1481 \text { to }-1470\end{array}$ & $\begin{array}{l}+ \\
+ \\
+\end{array}$ & $\begin{array}{l}\text { acccatatttag } \\
\text { ttgtatttttag } \\
\text { ggctaatttttg }\end{array}$ \\
\hline CRE (cAMP response element) & -1417 to -1406 & + & cctgacatcaag \\
\hline
\end{tabular}

of $\mathrm{Ca}^{2+}$ in intracellular stores (Legrand et al. 2001). TRPM8 may, with other ER-located $\mathrm{Ca}^{2+}$ pool regulators (e.g. ER $\left(\mathrm{Ca}^{2+}+\mathrm{Mg}^{2+}\right)$ ATPase), modulate the amount of $\mathrm{Ca}^{2+}$ in intracellular stores and subsequently regulate cell growth and proliferation (Fig. 5A).

While a number of proposals have been made, the normal functions of $\mathrm{Ca}^{2+}$ and $\mathrm{Na}^{+}$inflow through TRPM8 in prostate epithelial cells are not known, nor have the physiological activators of TRPM8 been described (Fig. 5A). It has been suggested that TRPM8 serves as a cold sensor in the prostate (Stein et al. 2004). Such a function has also recently been suggested for TRPM8 in the bladder (Tsukimi et al. 2005). TRPM8 may also be involved in other functions such as the regulation of proliferation and/or apoptosis (and hence the control of cell number) and in ion and protein secretion in prostate epithelial cells (Zhang \&
Barritt 2004). One interesting possibility comes from the recent observation that geraniol activates TRPM8 (Behrendt et al. 2004). The pyrophosphate ester of geraniol is an intermediate in cholesterol synthesis (Voet \& Voet 1990), and geraniol enhances cell proliferation in prostate epithelium (Paubert-Braquet et al. 1998). Thus it is possible that, in prostate epithelial cells, TRPM8 is involved in the regulation of cell proliferation and responds to geraniol as an intracellular messenger (Zhang \& Barritt 2004).

A more detailed study of the tissue and intracellular locations of the TRPM 8 protein in the prostate has shown that TRPM8 is principally expressed in prostate epithelial cells (Bidaux et al. 2005). A low level of TRPM8 expression was also found in smooth muscle cells. In prostate epithelial cells, the highest level of TRPM8 expression was seen in the apical region of secretory epithelial cells, with much lower amounts 
:

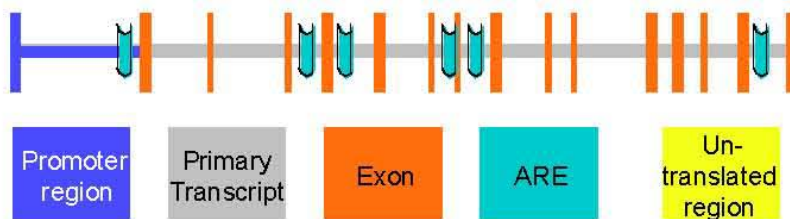

Figure 4 A schematic representation of the TRPM8 gene showing the locations of putative androgen response elements (ARE). The TRPM8 gene contains 24 exons and spans $95 \mathrm{~kb}$. The $5^{\prime}$ untranslated region ( -1 to $\left.-1500 \mathrm{bp}\right)$ is the predicted (GenoMatix) promoter region for driving TRPM8 transcription. Ten putative AREs, one in the promoter region and others in introns of the gene, can be identified (Zhang \& Barritt 2004).

of TRPM8 found in the basal regions. Expression of TRPM8 in secretory epithelial cells of the prostate decreased with time as the cells were grown in primary culture and became dedifferentiated. Bidaux et al. (2005) have suggested that TRPM8 is involved in the secretory function of prostate epithelial cells. Secretory products include citric acid, fibrinolysin, acid phosphatase, several other enzymes and lipids. Noting the androgen-dependence of TRPM8 expression and a role for androgens in oocyte fertilisation, these authors have suggested that one of the functions of androgenregulated TRPM8 is in fertilisation.

In addition to normal prostate epithelium, TRPM 8 is also detected in a number of urogenital tissues including testis, seminiferous tubules, scrotal skin, and

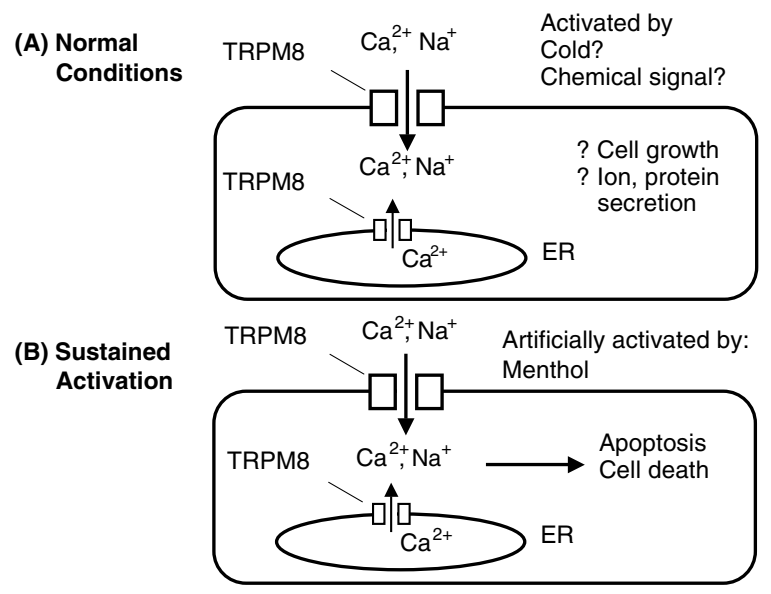

Figure 5 A schematic representation of the hypothesised functions of $\mathrm{Ca}^{2+}$ and $\mathrm{Na}^{+}$inflow mediated by TRPM8 in prostate cancer cells. (A) Prostate cancer cells under 'normal' conditions when TRPM8 is activated by physiological or pathophysiological activators. (B) Prostate cancer cells under conditions of sustained TRPM8 activation such as induced by menthol or other cooling chemical agents. bladder urothelium (Tsukimi et al. 2005) (Table 1). This systemic expression profile implies that TRPM8 may have yet to be identified roles associated with reproduction and/or sexuality.

On the basis of the observation that TRPM8 expression is upregulated in organ-confined prostate cancer cells and in a number of other cancerous cell types, TRPM8 could function as an oncogene. TRPM8 may contribute to the initiation, promotion and progression of carcinogenesis by disturbing $\mathrm{Ca}^{2+}$ homeostasis in pre-neoplastic cells. It has been reported that early pre-neoplastic cells are highly susceptible to apoptosis, whereas later pre-neoplastic cells are quite resistant (Preston et al. 1997). Moreover, increases in $\left[\mathrm{Ca}^{2+}\right]_{\text {cyt }}$ and intra-organelle $\mathrm{Ca}^{2+}$ play key roles in apoptosis (Mattson \& Chan 2003). Although several hypotheses have been proposed to explain the resistance of cells (such as androgenunresponsive prostate cancer cells) to apoptosis, a plausible mechanism involving $\mathrm{Ca}^{2+}$ signalling has been presented (reviewed in Prevarskaya et al. 2004) in which reduced $\mathrm{Ca}^{2+}$ levels in the ER were observed in early pre-neoplastic cells that undergo apoptosis compared with a higher level of stored $\mathrm{Ca}^{2+}$ in the ER in late pre-neoplastic cells. Over-expressed or upregulated TRPM8 channels could cause an increase in $\left[\mathrm{Ca}^{2+}\right]_{\text {cyt }}$ and an overfilling of ER $\mathrm{Ca}^{2+}$ store and this change in $\mathrm{Ca}^{2+}$ homeostasis would make the late pre-neoplastic cells more resistant to apoptotic stimuli and subsequently promote cell transformation into a neoplastic stage.

In addition, the detection of putative binding sites for tumour suppressor protein $\mathrm{p} 53$, prostate-specific homeodomain protein NKX3.1, and zinc-finger binding protein-89 (ZBP-89; Merchant et al. 2003) (Table 2) in the TRPM8 gene promoter region implies that TRPM8 may serve as a downstream target of 
tumour-suppressor genes. (ZBP-89 is a butyrateregulated co-activator of $\mathrm{p} 53$, and is able to induce p21(Waf1) gene expression through both p53dependent and -independent mechanisms to inhibit cell growth (Merchant et al. 2003).) Thus TRPM8 may be involved in the regulation of cell growth and carcinogenesis. Taken together, the above results suggest that TRPM8 is a novel prostate cancer biomarker, is likely to play an important role in the pathophysiology of prostate epithelial cells, and is a potential target for the action of drugs in the treatment of prostate cancer.

\section{The consequences of sustained activation of TRPM8 induced by pharmacological intervention in prostate cancer cells}

In contrast to the results that provide evidence that under 'normal' conditions TRPM8 is required for the survival of prostate epithelial cells, the non-physiological activation of TRPM8 by menthol can induce cell death in the androgen-sensitive LNCaP prostate cancer cell line (Zhang \& Barritt 2004). Moreno et al. (2005) further showed that some selective TRPM8 agonists inhibit the growth of TRPM8-positive tumours in mice by $77 \%$ compared with control untreated tumours (Moreno et al. 2005). This is presumably by inducing a sustained increase in the cytoplasmic $\mathrm{Ca}^{2+}$ and $\mathrm{Na}^{+}$concentrations (Fig. 5B). These effects most likely reflect a pathophysiological action of TRPM8, as it is unlikely that TRPM8 would normally be activated in a sustained manner. Interestingly, these findings may provide an explanation for the chemopreventive role of menthol on rat mammary tumours initiated by 7,12-dimethylbenz[a]anthracene (Russin et al. 1989) because TRPM8 is also expressed at significant levels in breast cancer cells (Table 1). Further experiments are needed to test the hypothesis and to evaluate whether menthol and its analogues could be promising agents for the chemoprevention of prostate and other cancers.

\section{Conclusions}

TRPM8 has clearly defined roles as a sensor for cooling in sensory neurones. While it is expressed in prostate cancer cells and is associated with the pathophysiology of these cells, tumorigenic progression and metastasis, its physiological or pathophysiological roles (in terms of the functions of $\mathrm{Ca}^{2+}$ and $\mathrm{Na}^{+}$which enter the cell via TRPM8) are not understood. They may be involved in sensing cold and/or chemical activators, in regulating the secretion of prostate epithelial cells, and/or in conveying signals which control cell growth and death. It is possible that TRPM8-mediated cool sensation is part of a more complex sensation network in the reproductive tract. In terms of molecular interactions, the mechanisms of activation of TRPM8 are rapidly being understood. These involve membrane potential, $\mathrm{PIP}_{2}$ and intracellular $\mathrm{Ca}^{2+}$. The TRPM8 over-expression profile in mainly organ-confined prostate cancers suggests a possible role of TRPM8 in the development of the cancer from the organ-confined stage to the metastatic stage.

TRPM8 is potentially a valuable diagnostic tissue marker and prognostic indicator for the progress of prostate cancer. Additional knowledge, which might establish this role for TRPM8 could include measurement of TRPM8 expression at the protein (as well as the mRNA) level. Further studies are needed to compare TRPM8 expression with other established prostate cancer markers in terms of accuracy and probability. The limitation of using TRPM 8 as a marker is that prostate tissues are needed for the examination of TRPM8 levels. The regulation of TRPM8 expression by androgens is important in terms of both fundamental knowledge and understanding the role of TRPM8 in prostate cancer. Further experiments might be directed at identifying androgen response elements and perhaps other hormone response elements in the promoter and intron regions, and at understanding the mechanisms underlying up-regulation of TRPM8 in cancerous tissues. Finally, TRPM 8 may be a potential target for pharmaceutical or genetic interventions for the treatment of prostate cancer and other cancers with overexpression of TRPM8. Further experiments might include screening for the specific and potent agonists for activation of the TRPM8 channel and exploring the strategy in vivo.

\section{Acknowledgements}

We gratefully acknowledge the contribution of Mrs Diana Kassos for the preparation of the typescript, and a grant from the Flinders University Collaborative Industry Research Scheme that supported some of the experimental work from the authors' laboratory described here. We thank the American Association for Cancer Research for permission to reprint Figure 3 which was originally published in Cancer Research. The authors declare that there is no conflict of interest that would prejudice the impartiality of this scientific work. 


\section{References}

Abe J, Hosokawa H, Okazawa M, Kandachi M, Sawada Y, Yamanaka K, Matsumura K \& Kobayashi S 2005 TRPM8 protein localization in trigeminal ganglion and taste papillae. Molecular Brain Research 136 91-98.

Andersson DA, Chase HW \& Bevan S 2004 TRPM8 activation by menthol, icilin, and cold is differentially modulated by intracellular pH. Journal of Neuroscience 24 5364-5369.

Babes A, Zorzon D \& Reid G 2004 Two populations of cold-sensitive neurons in rat dorsal root ganglia and their modulation by nerve growth factor. European Journal of Neuroscience 20 2276-2282.

Behrendt HJ, Germann T, Gillen C, Hatt H \& Jostock R 2004 Characterization of the mouse cold-menthol receptor TRPM8 and vanilloid receptor type-1 VR1 using a fluorometric imaging plate reader (FLIPR) assay. British Journal of Pharmacology 141 737-745.

Bidaux G, Roudbaraki M, Merle C, Crépin A, Delcourt P, Slomianny C, Thebault S, Bonnal J-L, Benahmed M, Cabon F et al. 2005 Evidence for specific TRPM8 expression in human prostate secretory epithelial cells: functional androgen receptor requirement. EndocrineRelated Cancer 12 367-382.

Bootman MD, Collins TJ, Mackenzie L, Roderick HL, Berridge MJ \& Peppiatt CM 2002 2-Aminoethoxydiphenyl borate (2-APB) is a reliable blocker of store-operated $\mathrm{Ca}^{2+}$ entry but an inconsistent inhibitor of $\mathrm{InsP}_{3}$-induced $\mathrm{Ca}^{2+}$ release. FASEB Journal 16 1145-1150.

Brauchi S, Orio P \& Latorre R 2004 Clues to understanding cold sensation: thermodynamics and electrophysiological analysis of the cold receptor TRPM8. PNAS 101 15494-15499.

Carter BS, Ewing CM, Ward WS, Treiger BF, Aalders TW, Schalken JA, Epstein JI \& Isaacs WB 1990 Allelic loss of chromosomes $16 \mathrm{q}$ and $10 \mathrm{q}$ in human prostate cancer. PNAS 87 8751-8755.

Chuang HH, Neuhausser WM \& Julius D 2004 The supercooling agent icilin reveals a mechanism of coincidence detection by a temperature-sensitive TRP channel. Neuron 43 859-869.

Clapham DE 2003 TRP channels as cellular sensors. Nature 426 517-524.

Culig Z, Klocker H, Eberle J, Kaspar F, Hobisch A, Cronauer MV \& Bartsch G 1993 DNA sequence of the androgen receptor in prostatic tumour cell lines and tissue specimens assessed by means of the polymerase chain reaction. Prostate 22 11-22.

Fuessel S, Sickert D, Meye A, Klenk U, Schmidt U, Schmitz M, Rost AK, Weigle B, Kiessling A \& Wirth MP 2003 Multiple tumor marker analyses (PSA, hK2, PSCA, trp-p8) in primary prostate cancers using quantitative RT-PCR. International Journal of Oncology 23 221-228.

He WW, Sciavolino PJ, Wing J, Augustus M, Hudson P, Meissner PS, Curtis RT, Shell BK, Bostwick DG, Tindall
DJ et al. 1997 A novel human prostate-specific, androgenregulated homeobox gene (NKX3.1) that maps to $8 \mathrm{p} 21$, a region frequently deleted in prostate cancer. Genomics 43 69-77.

Henshall SM, Afar DE, Hiller J, Horvath LG, Quinn DI, Rasiah KK, Gish K, Willhite D, Kench JG, GardinerGarden M et al. 2003 Survival analysis of genome-wide gene expression profiles of prostate cancers identifies new prognostic targets of disease relapse. Cancer Research 63 4196-4203.

Hu HZ, Gu Q, Wang C, Colton CK, Tang J, KinoshitaKawada M, Lee LY, Wood JD \& Zhu MX 2004 2-Aminoethoxydiphenyl borate is a common activator of TRPV1, TRPV2 and TRPV3. Journal of Biological Chemistry 279 35741-35748.

Hui K, Guo Y \& Feng Z-P 2005 Biophysical properties of menthol-activated cold receptor TRPM8 channels. Biochemical and Biophysical Research Communications 333 374-382.

Kiessling A, Füssel S, Schmitz M, Stevanovic S, Meye A, Weigle B, Klenk U, Wirth MP \& Rieber EP 2003 Identification of an HLA-A *0201-restricted T-cell epitope derived from the prostate cancer-associated protein trp-p8. Prostate 56 270-279.

Legrand G, Humez S, Slomianny C, Dewailly E, Vanden Abeele F, Mariot P, Wuytack F \& Prevarskaya N 2001 $\mathrm{Ca}^{2+}$ pools and cell growth. Evidence for sarcoendoplasmic $\mathrm{Ca}^{2+}$-ATPases $2 \mathrm{~B}$ involvement in human prostate cancer cell growth control. Journal of Biological Chemistry 276 47608-47614.

Liu B \& Qin F 2005 Functional control of cold- and menthol-sensitive TRPM8 ion channels by phosphatidylinositol 4,5-bisphosphate. Journal of Neuroscience 25 1674-1678.

Lundgren R, Kristoffersson U, Heim S, Mandahl N \& Mitelman F 1988 Multiple structural chromosome rearrangements, including $\operatorname{del}(7 q)$ and $\operatorname{del}(10 q)$, in an adenocarcinoma of the prostate. Cancer Genetics and Cytogenetics 35 103-108.

McKemy DD 2005 How cold is it? TRPM8 and TRPA1 in the molecular logic of cold sensation. Molecular Pain 116.

McKemy DD, Neuhausser WM \& Julius D 2002 Identification of a cold receptor reveals a general role for TRP channels in thermosensation. Nature 416 52-58.

Mattson MP \& Chan SL 2003 Calcium orchestrates apoptosis. Nature Cell Biology 5 1041-1043.

Merchant JL, Bai L \& Okada M 2003 ZBP-89 mediates butyrate regulations of gene expression. Journal of Nutrition 133 2456S-2460S.

Montell C 2005 The TRP superfamily of cation channels. Science's Signal Transduction Knowledge Environment 272 ref 3 .

Moreno O, Chen F, Duncan D, Graddis T, Laus R, McDole K, Morkowski S, Natarajan G \& Wang C 2005 Modulation of the Trp-p8 ion channel for the treatment of cancer. 96th American Association for Cancer Research Annual Meeting, April 16-20. Session ID 
(Poster): Experimental and Molecular Therapeutics $21-$ Identification of Molecular Targets 2. PNAS 462372.

Nealen ML, Gold MS, Thut PD \& Caterina MJ 2003

TRPM8 mRNA is expressed in a subset of coldresponsive trigeminal neurons from rat. Journal of Neurophysiology 90 515-520.

Nilius B, Talavera K, Owsianik G, Prenen J, Droogmans G \& Voets T 2005 Gating of TRP channels: a voltage connection? Journal of Physiology 567 35-44.

Okazawa M, Inoue W, Hori A, Hosokawa H, Matsumura K \& Kobayashi S 2004 Noxious heat receptors present in cold-sensory cells in rats. Neuroscience Letters 359 33-36.

Paubert-Braquet M, Cousse H, Raynaud JP, Mencia-Huerta JM \& Braquet P 1998 Effect of the lipidosterolic extract of Serenoa repens (Permixon) and its major components on basic fibroblast growth factor-induced proliferation of cultures of human prostate biopsies. European Urology 33 340-347.

Peier AM, Moqrich A, Hergarden AC, Reeve AJ, Andersson DA, Story GM, Earley TJ, Dragoni I, McIntyre P, Bevan S et al. 2002 A TRP channel that senses cold stimuli and menthol. Cell 108 705-715.

de la Pena E, Malkia A, Cabedo H, Belmonte C \& Viana F 2005 The contribution of TRPM8 channels to cold sensing in mammalian neurones. Journal of Physiology $567415-426$.

Phillips SM, Morton DG, Lee SJ, Wallace DM \& Neoptolemos JP 1994 Loss of heterozygosity of the retinoblastoma and adenomatous polyposis susceptibility gene loci and in chromosomes 10p, 10q and 16q in human prostate cancer. British Journal of Urology 73 390-395.

Prescott JL, Blok L \& Tindall DJ 1998 Isolation and androgen regulation of the human homeobox cDNA, NKX3.1. Prostate 35 71-80.

Preston GA, Barrett JC, Biermann JA \& Murphy E 1997 Effects of alterations in calcium homeostasis on apoptosis during neoplastic progression. Cancer Research $\mathbf{5 7}$ 537-542.

Prevarskaya N, Skryma R \& Shuba Y $2004 \mathrm{Ca}^{2+}$ homeostasis in apoptotic resistance of prostate cancer cells. Biochemical and Biophysical Research Communications 322 1326-1335.

Rohacs T, Lopes CMB, Michailidis I \& Logothetis DE 2005 $\mathrm{PI}(4,5) \mathrm{P}_{2}$ regulates the activation and desensitization of TRPM8 channels through the TRP domain. Nature Neuroscience 8 626-634.

Russin WA, Hoesly JD, Elson CE, Tanner MA \& Gould MN 1989 Inhibition of rat mammary carcinogenesis by monoterpenoids. Carcinogenesis 10 2161-2164.
Stein RJ, Santos S, Nagatomi J, Hayashi Y, Minnery BS, Xavier M, Patel AS, Nelson JB, Futrell WJ, Yoshimura N et al. 2004 Cool (TRPM8) and hot (TRPV1) receptors in the bladder and male genital tract. Journal of Urology 172 1175-1178.

Story GM, Peier AM, Reeve AJ, Eid SR, Mosbacher J, Hricik TR, Earley TJ, Hergarden AC, Andersson DA, Hwang SW et al. 2003 ANKTM1, a TRP-like channel expressed in nociceptive neurons, is activated by cold temperatures. Cell 112 819-829.

Thut PD, Wrigley D \& Gold MS 2003 Cold transduction in rat trigeminal ganglia neurons in vitro. Neuroscience 119 1071-1083.

Tominaga M \& Caterina MJ 2004 Thermosensation and pain. Journal of Neurobiology 61 3-12.

Tsavaler L, Shapero MH, Morkowski S \& Laus R 2001 Trp-p8, a novel prostate-specific gene, is up-regulated in prostate cancer and other malignancies and shares high homology with transient receptor potential calcium channel proteins. Cancer Research 61 3760-3769.

Tsukimi Y, Mizuyachi K, Yamasaki Y, Niki T \& Hayashi F 2005 Cold response of the bladder in guinea pig: involvement of transient receptor potential channel, TRPM8. Urology 65 406-410.

Voeller HJ, Augustus M, Madlike V, Bova GS, Carter KC \& Gelmann EP 1997 Coding region of NKX3.1, a prostatespecific homeobox gene on $8 \mathrm{p} 21$, is not mutated in human prostate cancers. Cancer Research 57 4455-4459.

Voet D \& Voet JG 1990 Biochemistry. New York: John Wiley $\&$ Sons.

Voets T, Droogmans G, Wissenbach U, Janssens A, Flockerzi V \& Nilius B 2004 The principle of temperaturedependent gating in cold- and heat-sensitive TRP channels. Nature 430 748-754.

Weil A, Moore SE, Waite NJ, Randall A \& Gunthorpe MJ 2005 Conservation of functional and pharmacological properties in the distantly related temperature sensors TRPV1 and TRPM8. Molecular Pharmacology 68 518-527.

Zhang L \& Barritt GJ 2004 Evidence that TRPM8 is an androgen-dependent $\mathrm{Ca}^{2+}$ channel required for the survival of prostate cancer cells. Cancer Research 64 8365-8373.

Zhang L, Jones S, Brody K, Costa M \& Brookes SJ 2004 Thermosensitive transient receptor potential channels in vagal afferent neurons of the mouse. American Journal of Physiology. Gastrointestinal Liver Physiology 286 G983-G991. 